\title{
Iterative approximation of split feasibility problem in real Hilbert spaces
}

\author{
J. N. Ezeora ${ }^{1^{*}}$, F.E. Bazuaye ${ }^{1}$
}

1. Department of Mathematics and Statistics, University of Port Harcourt, Nigeria.

*Corresponding author: jeremiah.ezeora@uniport@edu.ng

\section{Article Info}

Received: 25 April 2021

Accepted: 18 October 2021
Revised: 23 September 2021

Available online: 10 November 2021

\begin{abstract}
In this paper, we propose an iterative algorithm for finding solution of split feasibilty problem involving a $\lambda$-strictly pseudo-nonspreading map and asymptotically nonexpansive semigroups in two real Hilbert spaces. We prove weak and strong convergence theorems using the sequence obtained from the proposed algorithm. Finally, we applied our result to solve a monotone inclusion problem and present a numerical example to support our result.
\end{abstract}

Keywords: Nonexpansive semigroup, Asymptotically nonexpansive semigroup, Pseudo-nonspreading map, Strictly pseudocontractive map.

MSC2010: 47H09, 47H10, 49M05, 54H25

\section{Introduction}

The split feasibility problem (SFP) in finite dimensional Hilbert spaces was first introduced by Censor and Elfving [1] for modelling inverse problems which arise from phase retrievals and in medical image reconstruction. Since then, SFP has received much attention due to its applications in signal processing, image reconstruction, with particular progress in intensity-modulated radiation therapy, approximation theory, control theory, biomedical engineering, communications, and geophysics (see for e.g., [2], [3], [4], [5] and the references contained in them). Let $H_{1}$ and $H_{2}$ be two real Hilbert spaces, $C$ and $Q$ be nonempty closed convex subsets of $H_{1}$ and $H_{2}$, respectively. The SFP is formulated as follows; find a point $q \in H_{1}$ such that:

$$
q \in C \text { and } A q \in Q
$$

where $A: H_{1} \rightarrow H_{2}$ is a bounded linear map.

Suppose (1.1) has a solution, it is easy to see that $q \in C$ solves (1.1) if and only if it solves the following fixed point equation:

$$
p=P_{C}\left(I-\gamma A^{*}\left(I-P_{Q}\right) A\right) p, \quad p \in C,
$$

where $P_{C}$ and $P_{Q}$ are the projections onto $C$ and $Q$, respectively, $\gamma$ is a positive constant, and $A^{*}$ denotes the adjoint of $A$. We remark that equation (1.1) is called a split common fixed point 
problem (SCFPP) if $C$ and $Q$ are the set of fixed points of two nonlinear maps. If in (1.1), $C$ and $Q$ are intersections of fixed points sets of finite families of some nonlinear maps, the SFP is called multiple set split feasibilty problem (MSSFP) (see [4]). It is known that each nonempty closed convex subset of a Hilbert space is the set of fixed points of its projection, therefore, the SCFPP may be considered as a generalization of split feasibility problem.

A popular algorithm used to solve the SFP is the $C Q$ - algorithm introduced and studied by Byrne [2]:

$$
x_{n+1}=P_{C}\left(x_{n}-\gamma A^{*}\left(I-P_{Q}\right) A x_{n}\right), n \geq 1,
$$

where $\gamma \in\left(0, \frac{1}{\lambda}\right)$ with $\lambda$ being the spectral radius of the operator $A^{*} A$. As noted by Moudafi [6], the $C Q$ algorithm (1.3) is a special case of the $\operatorname{Krasnoselski-Mann}(K-M)$ algorithm. Precisely, using the formulation (1.1) of the SFP, we can apply the $K-M$ algorithm to the operator $P_{C}(I-$ $\left.\gamma A^{*}\left(I-P_{Q}\right) A\right)$ and obtain the following algorithm.

$$
x_{n+1}=\left(1-\alpha_{n}\right) x_{n}+\alpha_{n} P_{C}\left(I-\gamma A^{*}\left(I-P_{Q}\right) A\right) x_{n}, n \in \mathbb{N},
$$

where $\gamma \in\left(0, \frac{2}{\lambda}\right)$, and again $\lambda$ is the spectral radius of the operator $A^{*} A$. He further observed that if the control parameters $\left\{\alpha_{n}\right\}$ satisfy the condition $\sum_{n=1}^{\infty} \alpha_{n}\left(1-\alpha_{n}\right)=\infty$, Algorithm (1.4) converges weakly to a solution of the SFP.

Let $A: H_{1} \rightarrow H_{2}$ be a bounded linear operator, $U: H_{1} \rightarrow H_{1}$ and $T: H_{2} \rightarrow H_{2}$ be two quasinonexpansive operators with nonempty fixed-point sets FixU $=C$ and FixT $=Q$, and denote the solution set of the two-operator SCFPP by $\Gamma=\{y \in C: A y \in Q\}$. To solve SCFPP, Censor and Segal [7] proposed and proved, in finite-dimensional spaces, the convergence of the following algorithm:

$$
x_{n+1}=U\left(x_{n}+\gamma A^{t}(T-I) A x_{n}\right), n \in \mathbb{N},
$$

where $\gamma \in\left(0, \frac{2}{\lambda}\right)$, with $\lambda$ being the largest eigenvalue of the matrix $A^{t} A$ ( $t$ stands for matrix transposition). Inspired by algorithms (1.3), (1.4) and (1.5), Moudafi [6], introduced and studied in infinite dimensional Hilbert space the following sequence for two quasi -nonexpansive mappings.

$$
x_{n+1}=U_{\alpha_{n}}\left(x_{n}+\gamma A^{*}\left(T_{\beta}-I\right) A x_{n}\right), n \in \mathbb{N},
$$

where $\beta \in(0,1)$, and $\alpha_{n} \in(0,1)$ are relaxation parameters and $\gamma>0$.

Several other modifications of (1.3) have been made by many authors under different settings for solving problem (1.1) (see e.g., [6], [5], and the references contained in them).

In 2011, Osilike and Isiogugu [8] introduced an important class of nonlinear mappings called $k-$ strictly pseudo- nonspreading maps and obtained some convergence results for the said class of operators in real Hilbert spaces. Inspired by definition (3.1) of [8] and the definition of asymptotically strict pseudocontractive mappings given by Qihuo [9], Quan and Chang [10] introduced and studied a class of maps called $k$ - strictly asymptotically pseudo- nonspreading maps in a real Hilbert space. They obtained some convergence theorems for solving SCFPP involving the class of $k-$ strictly asymptotically pseudo- nonspreading mappings.

Recently, Cholamjiak and Shehu [11] obtained the following result for solving SCFPP involving asymptotically nonexpansive semigroup and total asymptotically strict pseudocontractive mapping.

Theorem 1.1. (Cholamjiak and Shehu [11]) Let $H_{1}$ and $H_{2}$ be two real Hilbert spaces, $A: H_{1} \rightarrow H_{2}$ is a bounded linear operator and $A^{*}: H_{2} \rightarrow H_{1}$ is the adjoint of $A ;\{S(t): t 0\}$ is a uniformly asymptotically regular nonexpansive semigroup on $H_{1} ; T: H_{2} \rightarrow H_{2}$ a uniformly L- Lipschitzian continuous and $\left(k,\left\{\mu_{n}\right\},\left\{\xi_{n}\right\}, \phi\right)$-total asymptotically strict pseudocontractive mapping satisfying $\sum \mu_{n}<\infty, \sum \xi_{n}<\infty$. conditions: Assume that $C:=\bigcap_{t 0} F(S(t)) \neq \emptyset, Q:=F(T) \neq \emptyset$ and $\Omega:=\left\{y \in C: A y \in Q=C \cap A^{-1}(Q)\right\} \neq \emptyset$. Let $\left\{x_{n}\right\}$ be the sequence generated by $x_{1} \in H_{1}$,

$$
\left\{\begin{array}{l}
u_{n}=\left(1-\alpha_{n}\right) x_{n}, \\
y_{n}=u_{n}+\gamma A^{*}\left(T^{n}-I\right) A u_{n}, \\
x_{n+1}=\left(1-\beta_{n}\right) y_{n}+\beta_{n} S\left(t_{n}\right) y_{n}, n \geq 1,
\end{array}\right.
$$


where $\left\{t_{n}\right\}$ is a sequence of real numbers, $\left\{\beta_{n}\right\},\left\{\alpha_{n}\right\}$ is a sequence in $(0,1)$, satisfy the following conditions;

(a) $0<\epsilon \leq \beta_{n} \leq b<1$; (b) $\gamma \in\left(0, \frac{1-k}{\|A\|^{2}}\right)$.

(b) $\mu_{n}=o\left(\alpha_{n}\right), \xi_{n}=o\left(\alpha_{n}\right), \lim \alpha_{n}=0 \sum \alpha_{n}=\infty$. Then the sequence $\left\{x_{n}\right\}$ converges strongly to an element of $\Omega$.

For more results on SCFPP (see, for e.g., [12] and the references contained therein).

Motivated by the recent research going on in the direction of split common fixed point problems, it is our purpose in this paper to construct an iterative algorithm for approximating solution of split feasibility problem involving a strictly pseudo-nonspreading map and asymptotically nonexpansive semigroup in real Hilbert spaces. Under some suitable conditions on the parameters, and the operator, it is proved that the proposed i algorithm converges weakly and strongly to a solution of SFP for the class of operators under consideration. The result obtained improve on the results of Chang et. al. [10], complements the results of; Cholamjiak and Shehu [11], Ezeora and Ogbonna [13], Moudafi [6] and many others.

\section{Preliminaries}

Let $H$ be a real Hilbert space. We shall denote $x_{n} \rightarrow v^{*}$ and $x_{n} \rightarrow v^{*}$ as $n \rightarrow \infty$ to indicate that the sequence $\left\{x_{n}\right\}$ converges weakly to $v^{*}$ and converges strongly to $v^{*}$, respectively. The following definitions and lemmas will be used in the sequel.

Definition 2.1. Let $T: H \rightarrow H$ be a map. $T$ is called:

(i) nonspreading if for each $u, v \in H$

$$
\|T u-T v\|^{2} \leq\|u-v\|^{2}+2\langle u-T u, v-T v\rangle,
$$

(ii) $\lambda$-strictly pseudo-nonspreading if for each $u, v \in H$ there exists $\lambda \in[0,1[$ such that

$$
\|T u-T v\|^{2} \leq\|u-v\|^{2}+\lambda\|(I-T) u-(I-T) v\|^{2}+2\langle u-T u, v-T v\rangle,
$$

(iii) Lipschitz if for each $u, v \in H$ there exists $L>0$ such that

$$
\|T u-T v\| \leq L\|u-v\|,
$$

(iv) nonexpansive if for each $u, v \in H, L=1$ in the inequality of (iii).

(v) quasi nonexpansive if

$$
\|T u-q\| \leq\|u-q\| \quad \forall(u, q) \in H \times F(T) .
$$

(vi) firmly nonexpansive if

$$
\|T u-T v\|^{2} \leq\|u-v\|^{2}-\|(u-v)-(T u-T v)\|^{2} \quad \forall(u, v) \in H \times H .
$$

(vii) firmly quasi nonexpansive if

$$
\|T u-q\|^{2} \leq\|u-q\|^{2}-\|(u-T u)\|^{2} \quad \forall(u, q) \in H \times F(T) .
$$

Definition 2.2. A map $T: H \rightarrow H$ is called semi-compact, if for any sequence $\left\{x_{n}\right\}$ in $H$ such that $\lim \left\|x_{n}-T x_{n}\right\|=0$, there exists a subsequence $\left\{x_{n_{j}}\right\}$ of $\left\{x_{n}\right\}$ such that $x_{n_{j}} \rightarrow p \in H$.

Definition 2.3. A map $T: H \rightarrow H$ is called $\left\{k_{n}\right\}$-asymptotically nonexpansive if for each $u, v \in H$ there exists a sequence $\left\{k_{n}\right\} \subset\left[1, \infty\left[\right.\right.$ with $k_{n} \rightarrow 1$ such that

$$
\left\|T^{n} u-T^{n} v\right\| \leq k_{n}\|u-v\| .
$$


Example 2.4. Let $C$ be a unit ball in a real Hilbert space $H$. Let $T: C \rightarrow C$ be a map defined by

$$
T:\left(u_{1}, u_{2}, \cdots\right) \rightarrow\left(0, u_{1}^{2}, a_{2} u_{2}, a_{3} u_{3}, \cdots\right),
$$

where $\left\{a_{i}\right\}$ is a sequence in $(0,1)$ such that $\Pi_{i=2}^{n} a_{i}=\frac{1}{2}$. Goebel and Kirk [14] proved that

(i) $\|T u-T v\| \leq 2\|u-v\|, \quad \forall u, v \in C$

(ii) $\left\|T^{n} u-T^{n} v\right\| \leq 2 \Pi_{i=2}^{n} a_{i}\|u-v\|, \quad \forall n \geq 2, u, v \in C$.

Denote $k_{1}^{\frac{1}{2}}=2, k_{n}^{\frac{1}{2}}=2 \prod_{i=2}^{n} a_{i}=1, \quad n \geq 2$. Then, $\lim k_{n}=\lim \left(2 \prod_{i=2}^{n} a_{i}\right)^{2}=1$.

Thus, for each $u, v \in C$, we have:

$$
\left\|T^{n} u-T^{n} v\right\|^{2} \leq k_{n}\|u-v\|^{2},
$$

which implies that $T$ is $\left\{k_{n}\right\}$-asymptotically nonexpansive.

Definition 2.5. A one-parameter family $\mathcal{F}:=\{T(t): t \geq 0\}$ of $H$ into itself is called a strongly continuous semigroup of Lipschitzian map on $H$ if it satisfies the following conditions:

(i) $T(0) u=u$, for all $u \in H$;

(ii) $T(s+t)=T(s) T(t)$, for all $s, t \geq 0$;

(iii) for each $u \in H$ the map $t \mapsto T(t) u$ is continuous;

(iv) for each $t>0$, there exists a bounded measurable function $L(t):[0, \infty[\rightarrow[0, \infty[$ such that

$$
\|T(t) u-T(t) v\| \leq L(t)\|u-v\|,
$$

for all $u, v \in H$.

A strongly continuous semigroup of Lipschitzian map $\mathcal{F}$ is called strongly continuous semigroup of nonexpansive maps if $L(t)=1$, for each $t>0$, and strongly continuous semigroup of asymptotically nonexpansive if $\lim _{\sup _{t \rightarrow \infty}} L(t) \leq 1$. We note that for asymptotically nonexpansive semigroup $\mathcal{F}$, we can always assume that $\{L(t)\}_{t>0}$ is such that $L(t) \geq 1$ for each $t>0, L(t)$ is nonincreasing in $t$, and $\lim _{t \rightarrow \infty} L(t)=1$; or we replace $L(t)$, for each $t>0$, with $L(t):=\max \left\{\sup _{s \geq t} L(s), 1\right\}$. We denote the set of fixed points of $\mathcal{F}$ by

$$
F i x(\mathcal{F})=\{u \in H: T(t) u=u, 0 \leq t\}=\cap_{t \geq 0} F(T(t)) .
$$

If $\mathcal{F}$ satisfies $(i)-($ iii $)$ and

$$
\limsup _{t \rightarrow \infty u \in M}\|T(t) u-T(s) T(t) u\|=0, \quad \forall s>0 \quad \text { where } M \subseteq C \subset H \text { is bounded. }
$$

Then $\mathcal{F}$ is called uniformly asymptotically regular on $C$.

Example 2.6. (See Lemma 2.7 of [15]) Let D be a bounded closed convex subset of $H$, and $\mathcal{F}=$ $\{S(t): t>0\}$ be a nonexpansive semigroup on $H$ such that Fix $(\mathcal{F})$ is nonempty. For each $h>0$, set $\sigma_{t}(x)=\frac{1}{t} \int_{0}^{t} S(s) x d s$, then

$$
\limsup _{t \rightarrow \infty x \in D}\left\|S(h)\left(\sigma_{t} x\right)-\sigma_{t}(x)\right\|=0 .
$$

The set $\left\{\sigma_{t}: t>0\right\}$ defined above is a uniformly asymptotically regular nonexpansive semigroup, (see [16]).

Example 2.7. Let $E$ be a uniformly convex Banach space which admits a weakly continuous duality map. Let $L(E)$ be the space of all bounded linear operators on $E$. For $\Psi \in L(E)$, define $\mathcal{F}:=\{T(t)$ : $\left.t \in \mathbb{R}^{+}\right\}$of bounded linear operators by using the following exponential expression:

$$
T(t)=\exp ^{-t \Psi}: \sum_{k=0}^{\infty} \frac{(-1)^{k}}{k !} t^{k} \Psi^{k} .
$$


Then, clearly, the family $\mathcal{F}:=\left\{T(t): t \in \mathbb{R}^{+}\right\}$satisfies the semigroup properties.

Moreover, this family forms a one parameter semigroup of self-mappings of E because $\exp ^{-t \Psi}=$ $\left[\exp ^{t \Psi}\right]^{-1}: E \rightarrow E$ exists for each $t \in \mathbb{R}^{+}$.

Definition 2.8. A Banach space $E$ is said to satisfy Opial's condition if for any sequence $\left\{x_{n}\right\} \in E$, $x_{n} \rightarrow x$, for any $y \in E$ with $y \neq x$, we have

$$
\liminf _{n \rightarrow \infty}\left\|x_{n}-x\right\|<\liminf _{n \rightarrow \infty}\left\|x_{n}-y\right\| .
$$

Lemma 2.9. Let $H$ be a real Hilbert space. Then, for all $x, y \in H, \lambda \in[0,1]$, we have:

$$
\|\lambda x+(1-\lambda) y\|^{2}=\lambda\|x\|^{2}+(1-\lambda)\|y\|^{2}-\lambda(1-\lambda)\|x-y\|^{2} .
$$

Lemma 2.10. (Tan and $X u,[17])$ Let $\left\{a_{n}\right\}$ and $\left\{\alpha_{n}\right\}$ be sequences of nonnegative real numbers satisfying the following relation:

$$
a_{n+1} \leq\left(1+\alpha_{n}\right) a_{n}, \quad \forall n \geq 1
$$

If $\sum \alpha_{n}<\infty$, then $\lim a_{n}$, exists and if $\lim \inf a_{n}=0$, then, $\lim a_{n}=0$.

Lemma 2.11. (Quan and Chang, [10]) Let $C$ be a nonempty closed convex subset of a real Hilbert space $H$. Let $T: C \rightarrow C$ be a continuous $k$-asymptotically strictly pseudo-nonspreading map such that $F(T) \neq \emptyset$. Then, $F(T)$ is closed and convex.

Lemma 2.12. (Chang et al., [18]) Let $X$ be a real uniformly convex Banach space, $C$ be a nonempty closed subset of $X$. Let $T: C \rightarrow C$ be an asymptotically nonexpansive mapping. Then, $I-T$ is demi-closed at zero.

Lemma 2.13. (Osilike and Isiogugu, [8]) Let $H$ be a real Hilbert space, $C$ be a nonempty and closed convex subset of $H$, and $T: C \rightarrow C$ be a $k$-strictly pseudo-nonspreading mapping. Then, the following hold:

(a) If Fix $(T) \neq \emptyset$, then, it is closed and convex.

(b) $T$ is demi-closed at 0 .

Lemma 2.14. (see [10]) Let $K$ be a nonempty closed convex subset of a real Hilbert space H, and let $T: K \rightarrow K$ be a continuous - asymptotically strictly pseudo-nonspreading mapping. If $F(T) \neq \emptyset$, then it is a closed and convex subset of $H$.

Lemma 2.15. (see [10]) Let $K$ be a nonempty closed convex subset of a real Hilbert space H, and let $T: K \rightarrow K$ be a continuous $\kappa-$ symptotically strictly pseudo-nonspreading mapping. Then $(I-T)$ is demiclosed at 0 , that is, if $x_{n} \rightarrow x^{*}$ and $\lim \sup _{m \rightarrow \infty} \lim \sup _{n \rightarrow \infty}\left\|\left(I-T^{m}\right) x_{n}\right\|=0$, then $\left\|(I-T) x^{*}\right\|=0$.

Lemma 2.16. ( Moudafi [6]) Let $T$ be a quasi-nonexpansive mapping, and set $T_{\alpha}:=(1-\alpha) I+$ $\alpha T$, for $\alpha \in(0,1]$. Then, the following properties are reached for all $(x, q) \in H \times F(T)$ :

(1.) $\langle x-T x, x-q\rangle \geq \frac{1}{2}\|x-T x\|^{2}$ and $\langle x-T x, q-T x\rangle \leq \frac{1}{2}\|x-T x\|^{2}$.

(2.) $\left\|T_{\alpha} x-q\right\|^{2} \leq\|x-q\|^{2}-\alpha(1-\alpha)\|T x-x\|^{2}$.

(3.) $\left\langle x-T_{\alpha} x, x-q\right\rangle \geq \frac{\alpha}{2}\|x-T x\|^{2}$.

Remark 2.17. Every Hilbert space $H$ satisfies the opial's condition.

\section{Main Result}

Theorem 3.1. Let $H_{1}$ and $H_{2}$ be real Hilbert spaces. Let $A: H_{1} \rightarrow H_{2}$ be a bounded linear map such that $A \neq 0$, and $A^{*}$ be the adjoint of $A$. Let $\{S(t): t \geq 0\}: H_{1} \rightarrow H_{1}$ be a uniformly 
asymptotically regular asymptotically nonexpansive semigroup with a bounded measurable function $L(t):\left[0, \infty\left[\rightarrow\left[0, \infty\left[\right.\right.\right.\right.$ such that $\lim _{t \rightarrow \infty} L(t)=1$ and $M_{0}:=\bigcap_{t \geq 0} F(S(t)) \neq \emptyset$. Let $T: H_{2} \rightarrow H_{2}$ be an L-Lipschitz and $\lambda$-strictly pseudo-nonspreading map such that $F(T) \neq \emptyset$. Let the sequence $\left\{x_{n}\right\}$ be generated by

$$
\left\{\begin{array}{l}
x_{1} \in H_{1} \\
u_{n}=x_{n}+\gamma A^{*}(T-I) A x_{n} ; \\
\quad x_{n+1}=(1-\beta) u_{n}+\beta S\left(t_{n}\right) u_{n},
\end{array}\right.
$$

where $\beta \in(0,1), \gamma>0$ with $0<\gamma<\frac{1-\lambda}{M\|A\|^{2}}$ and $\left\{t_{n}\right\}$ is a sequence of positive real numbers satisfying the following conditions:

$\left(C_{1}\right) \lim t_{n}=\infty, \quad\left(C_{2}\right) \sum_{n=1}^{\infty}\left(L^{2}\left(t_{n}\right)-1\right)<\infty \quad$ and $\left(C_{3}\right) M=\sup _{n} L\left(t_{n}\right)$.

(A) Suppose $\mathcal{D}:=\left\{p \in M_{0}: A p \in F(T)\right\} \neq \emptyset$. Then, the sequence $\left\{x_{n}\right\}$ converges weakly to $p \in \mathcal{D}$.

(B) If in addition there exists $S\left(t_{*}\right) \in\{S(t): t \geq 0\}$ that is semi-compact. Then, the sequence $\left\{x_{n}\right\}$ converges strongly to $p \in \mathcal{D}$.

Proof. We divide our proof into five steps.

Step 1. We prove that $\lim \left\|x_{n}-p\right\|$ exists.

Let $p \in \mathcal{D}$. Then, $p \in M_{0}$ and $A p \in F(T)$. We compute as follows:

$$
\begin{aligned}
\left\|u_{n}-p\right\|^{2} & =\left\|x_{n}+\gamma A^{*}(T-I) A x_{n}-p\right\|^{2} \\
& =\left\|x_{n}-p\right\|^{2}+2 \gamma\left\langle x_{n}-p, A^{*}(T-I) A x_{n}\right\rangle+\gamma^{2}\left\langle A^{*}(T-I) A x_{n}, A^{*}(T-I) A x_{n}\right\rangle \\
& =\left\|x_{n}-p\right\|^{2}+2 \gamma\left\langle x_{n}-p, A^{*}(T-I) A x_{n}\right\rangle+\gamma^{2}\left\langle A A^{*}(T-I) A x_{n},(T-I) A x_{n}\right\rangle \\
& \leq\left\|x_{n}-p\right\|^{2}+2 \gamma\left\langle A\left(x_{n}-p\right),(T-I) A x_{n}\right\rangle+\gamma^{2}\|A\|^{2}\left\|(T-I) A x_{n}\right\|^{2} .
\end{aligned}
$$

Since $T$ is $\lambda$ - strictly pseudo-nonspreading and $A p \in F(T)$, then, we have:

$$
\left\|T A x_{n}-A p\right\|^{2} \leq\left\|A x_{n}-A p\right\|^{2}+\lambda\left\|(T-I) A x_{n}\right\|^{2} .
$$

Also,

$$
\begin{aligned}
\left\|T A x_{n}-A p\right\|^{2} & =\left\|\left(T A x_{n}-A x_{n}\right)+\left(A x_{n}-A p\right)\right\|^{2} \\
& =\left\|T A x_{n}-A x_{n}\right\|^{2}+\left\|A x_{n}-A p\right\|^{2}+2\left\langle T A x_{n}-A x_{n}, A x_{n}-A p\right\rangle .
\end{aligned}
$$

Using equations (3.2) and (3.3), we have:

$$
2\left\langle T A x_{n}-A x_{n}, A x_{n}-A p\right\rangle \leq(\lambda-1)\left\|(T-I) A x_{n}\right\|^{2} .
$$

From inequality (3.5), we have:

$$
\begin{aligned}
\left\langle T A x_{n}-A x_{n}, T A x_{n}-A p\right\rangle & =\left\|(T-I) A x_{n}\right\|^{2}+\left\langle T A x_{n}-A x_{n}, A x_{n}-A p\right\rangle \\
& \leq \frac{\lambda+1}{2}\left\|(T-I) A x_{n}\right\|^{2} .
\end{aligned}
$$

From inequality (3.2), we obtain that:

$$
\begin{aligned}
2 \gamma\left\langle A\left(x_{n}-p\right),(T-I) A x_{n}\right\rangle & =2 \gamma\left\langle A\left(x_{n}-p\right)+(T-I) A x_{n}-(T-I) A x_{n},(T-I) A x_{n}\right\rangle \\
& =2 \gamma\left\langle T A x_{n}-A p,(T-I) A x_{n}\right\rangle-2 \gamma\left\|(T-I) A x_{n}\right\|^{2} .
\end{aligned}
$$

Substituting inequality (3.6) in inequality (3.7), we have:

$$
\begin{aligned}
2 \gamma\left\langle A\left(x_{n}-p\right),(T-I) A x_{n}\right\rangle & \leq \gamma(\lambda+1)\left\|(T-I) A x_{n}\right\|^{2}-2 \gamma\left\|(T-I) A x_{n}\right\|^{2} \\
& =\gamma(\lambda-1)\left\|(T-I) A x_{n}\right\|^{2} .
\end{aligned}
$$


Substituting inequality (3.8) in inequality (3.2), we have:

$$
\begin{aligned}
\left\|u_{n}-p\right\|^{2} & \leq\left\|x_{n}-p\right\|^{2}+\gamma(\lambda-1)\left\|(T-I) A x_{n}\right\|^{2}+\gamma^{2}\|A\|^{2}\left\|(T-I) A x_{n}\right\|^{2} \\
& =\left\|x_{n}-p\right\|^{2}-\gamma\left[1-\left(\lambda+\gamma\|A\|^{2}\right)\right]\left\|(T-I) A x_{n}\right\|^{2} .
\end{aligned}
$$

By Lemma 2.9, equation (3.1) and inequality (3.9), we have:

$$
\begin{aligned}
\left\|x_{n+1}-p\right\|^{2}= & \left\|(1-\beta) u_{n}+\beta S\left(t_{n}\right) u_{n}-p\right\|^{2} \\
= & (1-\beta)\left\|u_{n}-p\right\|^{2}+\beta\left\|S\left(t_{n}\right) u_{n}-p\right\|^{2}-\beta(1-\beta)\left\|S\left(t_{n}\right) u_{n}-u_{n}\right\|^{2} \\
\leq & (1-\beta)\left\|u_{n}-p\right\|^{2}+\beta L^{2}\left(t_{n}\right)\left\|u_{n}-p\right\|^{2}-\beta(1-\beta)\left\|S\left(t_{n}\right) u_{n}-u_{n}\right\|^{2} \\
= & {\left[1+\beta\left(L^{2}\left(t_{n}\right)-1\right)\right]\left\|u_{n}-p\right\|^{2}-\beta(1-\beta)\left\|S\left(t_{n}\right) u_{n}-u_{n}\right\|^{2} } \\
= & {\left[1+\beta\left(L^{2}\left(t_{n}\right)-1\right)\right]\left[\left\|x_{n}-p\right\|^{2}-\gamma\left[1-\left(\lambda+\gamma\|A\|^{2}\right)\right]\left\|(T-I) A x_{n}\right\|^{2}\right] } \\
& -\beta(1-\beta)\left\|S\left(t_{n}\right) u_{n}-u_{n}\right\|^{2} \\
\leq & {\left[1+\beta\left(L^{2}\left(t_{n}\right)-1\right)\right]\left\|x_{n}-p\right\|^{2}-\gamma\left[1-\left(\lambda+\gamma\|A\|^{2}\right)\right]\left\|(T-I) A x_{n}\right\|^{2} } \\
& -\beta(1-\beta)\left\|S\left(t_{n}\right) u_{n}-u_{n}\right\|^{2} \\
\leq & {\left[1+\beta\left(L^{2}\left(t_{n}\right)-1\right)\right]\left\|x_{n}-p\right\|^{2} . }
\end{aligned}
$$

Since $\sum\left(L^{2}\left(t_{n}\right)-1\right)<\infty$, by Lemma 2.10 , we have that

$$
\lim \left\|x_{n}-p\right\| \quad \text { exists }
$$

Hence, $\left\{x_{n}\right\}$ and $\left\{u_{n}\right\}$ are bounded.

Step 2. We prove that $\lim \left\|x_{n+1}-x_{n}\right\|=0$.

From inequality (3.10), set $\eta:=\frac{1}{\beta(1-\beta)}$ and $\varpi:=\frac{1}{\gamma\left[1-\left(\lambda+\gamma\|A\|^{2}\right)\right]}$. Then, we have:

$$
\begin{aligned}
& \left\|S\left(t_{n}\right) u_{n}-u_{n}\right\| \leq \eta\left[\beta\left(L^{2}\left(t_{n}\right)-1\right)\left\|x_{n}-p\right\|^{2}+\left\|x_{n}-p\right\|^{2}-\left\|x_{n+1}-p\right\|^{2}\right], \\
& \left\|(T-I) A x_{n}\right\|^{2} \leq \varpi\left[\beta\left(L^{2}\left(t_{n}\right)-1\right)\left\|x_{n}-p\right\|^{2}+\left\|x_{n}-p\right\|^{2}-\left\|x_{n+1}-p\right\|^{2}\right] .
\end{aligned}
$$

By condition $\left(C_{2}\right), \beta\left(L^{2}\left(t_{n}\right)-1\right) \rightarrow 0$. Applying this and conclusion (3.12) in (3.13) and (3.14) and noticing that $\left\{\left\|x_{n}-p\right\|\right\}$ is bounded, we have:

$$
\lim \left\|S\left(t_{n}\right) u_{n}-u_{n}\right\|=0 \quad \text { and } \quad \lim \left\|(T-I) A x_{n}\right\|=0 .
$$

Furthermore, from inequality (3.9) and equation (3.1), we have:

$$
\lim \left\|u_{n}-p\right\| \text { exists and }\left\|x_{n}-u_{n}\right\| \leq \gamma\|A\|\left\|(T-I) A x_{n}\right\| \rightarrow 0 \text { as } n \rightarrow \infty .
$$

Now,

$$
\begin{aligned}
\left\|x_{n+1}-x_{n}\right\| & =\left\|(1-\beta) u_{n}+\beta S\left(t_{n}\right) u_{n}-x_{n}\right\| \\
& =\left\|(1-\beta)\left(x_{n}+\gamma A^{*}(T-I) A x_{n}\right)+\beta S\left(t_{n}\right) u_{n}-x_{n}\right\| \\
& =\left\|(1-\beta) \gamma A^{*}(T-I) A x_{n}+\beta\left(S\left(t_{n}\right) u_{n}-x_{n}\right)\right\| \\
& =\left\|(1-\beta) \gamma A^{*}(T-I) A x_{n}+\beta\left(S\left(t_{n}\right) u_{n}-u_{n}\right)+\beta\left(u_{n}-x_{n}\right)\right\| \\
& \leq \gamma\|A\|\left\|(T-I) A x_{n}\right\|+\beta\left\|\left(S\left(t_{n}\right) u_{n}-u_{n}\right)\right\|+\beta\left\|u_{n}-x_{n}\right\| \rightarrow 0 \text { as } n \rightarrow \infty .
\end{aligned}
$$

Step 3. We show that $\lim \left\|u_{n}-S(t) u_{n}\right\|=0, \quad \forall t \geq 0$.

Since $\{S(t): t \geq 0\}$ is uniformly asymptotically regular and $\lim t_{n}=\infty$, also, $t \mapsto S(\cdot) x$ is continuous for each $x \in H_{1}$, then, we have:

$$
\lim _{n \rightarrow \infty}\left\|S(t) S\left(t_{n}\right) u_{n}-S\left(t_{n}\right) u_{n}\right\| \leq \lim _{n \rightarrow \infty} \sup _{x \in M}\left\|S(t) S\left(t_{n}\right) x-S\left(t_{n}\right) x\right\| \rightarrow 0 .
$$


Thus,

$$
\left\|u_{n}-S(t) u_{n}\right\| \leq\left\|u_{n}-S\left(t_{n}\right) u_{n}\right\|+\left\|S\left(t_{n}\right) u_{n}-S(t) S\left(t_{n}\right) u_{n}\right\|+\left\|S(t) S\left(t_{n}\right) u_{n}-S(t) u_{n}\right\| .
$$

This implies that $\left\|u_{n}-S(t) u_{n}\right\| \rightarrow 0$ as $n \rightarrow \infty$.

Step 4. We show that the sequence $\left\{x_{n}\right\}$ converges weakly to a point $p \in \mathcal{D}$.

Since $\left\{x_{n}\right\}$ is bounded, then, there exists a subsequence $\left\{x_{n_{j}}\right\}$ of $\left\{x_{n}\right\}$ such that $x_{n_{j}} \rightarrow p$ as $j \rightarrow \infty$.

But $S(t)$ is asymptotically nonexpansive, for each $t \geq 0$. Then, by Lemma 2.12, $S(t)$ is demi-closed at 0 . Hence, $p \in F(S(t)) \forall t \geq 0$. That is $p \in \cap_{t \geq 0} F(S(t))$.

Furthermore, $A$ is a bounded linear operator. Hence, $\left\{A x_{n_{j}}\right\}$ converges weakly to $A p$. From equation (3.15), we obtain that $\lim \left\|(T-I) A x_{n_{j}}\right\|=0$. By demi-closedness of $T$ at 0 , it follows that $A p \in F(T)$. Hence, $p \in \mathcal{D}$.

Next we show that $p$ is unique. Assume for contradiction, that there exists another subsequence $\left\{x_{n_{k}}\right\}$ of $\left\{x_{n}\right\}$ such that $x_{n_{k}} \rightarrow u^{*}$ as $k \rightarrow \infty$, where $p \neq u^{*}$. Recall that from Step 4 above $\left\{x_{n_{j}}\right\}$ is a subsequence of $\left\{x_{n}\right\}$ such that $x_{n_{j}} \rightarrow p$ as $j \rightarrow \infty$. Using similar arguments as those of step 4, one can show that $u^{*} \in \mathcal{D}$. By Remark 2.17, we know that $H_{1}$ satisfies Opial condition, hence we have:

$$
\begin{aligned}
\liminf _{k \rightarrow \infty}\left\|x_{n_{k}}-p\right\| & <\liminf _{k \rightarrow \infty}\left\|x_{n_{k}}-u^{*}\right\| \\
& =\lim _{n \rightarrow \infty}\left\|x_{n}-u^{*}\right\| \\
& =\liminf _{j \rightarrow \infty}\left\|x_{n_{j}}-u^{*}\right\| \\
& <\liminf _{j \rightarrow \infty}\left\|x_{n_{j}}-p\right\| \\
& =\lim _{n \rightarrow \infty}\left\|x_{n}-p\right\| \\
& =\liminf _{k \rightarrow \infty}\left\|x_{n_{k}}-p\right\| .
\end{aligned}
$$

Hence, a contradiction. Therefore, $x_{n} \rightarrow p$ as $n \rightarrow \infty$. This completes the proof conclusion $(A)$.

Next, we proof for condition $(B)$

Since there exists $S\left(t_{*}\right) \in\{S(t): t \geq 0\}$ that is semi-compact and $\lim \left\|u_{n}-S(t) u_{n}\right\|=0 \forall t \geq 0$, then, there exists a subsequence $\left\{u_{n_{j}}\right\}$ of $\left\{u_{n}\right\}$ such that $\left\{u_{n_{j}}\right\}$ converges strongly to $\varkappa^{*} \in H_{1}$. Applying equation (3.16) and the fact that $\left\{u_{n_{j}}\right\}$ converges strongly to $\varkappa^{*} \in H_{1}$, we obtain that there exists a subsequence $\left\{x_{n_{j}}\right\}$ of $\left\{x_{n}\right\}$ which converges strongly to $\varkappa^{*}$. Since $\left\{x_{n}\right\}$ converges weakly to $p$, then, $\varkappa^{*}=p$. Furthermore, $\lim \left\|x_{n}-p\right\|$ exists and $\lim \left\|x_{n_{j}}-p\right\|=0$. Therefore, $\left\{x_{n}\right\}$ converges strongly to $p \in \mathcal{D}$.

This completes the proof conclusion $(B)$.

Corollary 3.1. Let $H_{1}$ and $H_{2}$ be real Hilbert spaces. Let $A: H_{1} \rightarrow H_{2}$ be a bounded linear map such that $A \neq 0$, and $A^{*}$ be the adjoint of $A$. Let $\{S(t): t \geq 0\}: H_{1} \rightarrow H_{1}$ be a nonexpansive semigroup with a bounded measurable function $L(t):[0, \infty[\rightarrow[0, \infty[$ such that $L(t)=1, \forall t>0$ and $M:=\bigcap_{t \geq 0} F(S(t)) \neq \emptyset$. Let $T: H_{2} \rightarrow H_{2}$ be an L-Lipschitz and $\lambda$-strictly pseudo-nonspreading map such that $F(T) \neq \emptyset$. Let the sequence $\left\{x_{n}\right\}$ be generated by

$$
\left\{\begin{array}{l}
x_{1} \in H_{1} \\
u_{n}=x_{n}+\gamma A^{*}(T-I) A x_{n} \\
\quad x_{n+1}=(1-\beta) u_{n}+\beta S(t) u_{n},
\end{array}\right.
$$

where $\beta \in(0,1), \gamma>0$ with $0<\gamma<\frac{1-\lambda}{\|A\|^{2}}$.

(A) Suppose $\mathcal{D}:=\{p \in M: A P \in F(T)\} \neq \emptyset$. Then, the sequence $\left\{x_{n}\right\}$ converges weakly to $p \in \mathcal{D}$. (B) If in addition there exists $S\left(t_{*}\right) \in\{S(t): t \geq 0\}$ that is semi-compact. Then, the sequence $\left\{x_{n}\right\}$ converges strongly to $p \in \mathcal{D}$. 
Corollary 3.2. Let $H_{1}$ and $H_{2}$ be real Hilbert spaces. Let $A: H_{1} \rightarrow H_{2}$ be a bounded linear map such that $A \neq 0$, and $A^{*}$ be the adjoint of $A$. Let $S: H_{1} \rightarrow H_{1}$ be a nonexpansive map and $F(S) \neq \emptyset$. Let $\mathrm{T}: \mathrm{H}_{2} \rightarrow \mathrm{H}_{2}$ be an L-Lipschitz and $\lambda$-strictly pseudo-nonspreading map such that $F(T) \neq \emptyset$. Let the sequence $\left\{x_{n}\right\}$ be generated by

$$
\left\{\begin{array}{l}
x_{1} \in H_{1} \\
u_{n}=x_{n}+\gamma A^{*}(T-I) A x_{n} \\
x_{n+1}=(1-\beta) u_{n}+\beta S u_{n},
\end{array}\right.
$$

where $\beta \in(0,1), \gamma>0$ with $0<\gamma<\frac{1-\lambda}{\|A\|^{2}}$.

(A) Suppose $\mathcal{D}:=\{p \in F(S): A P \in F(T)\} \neq \emptyset$. Then, the sequence $\left\{x_{n}\right\}$ converges weakly to $p \in \mathcal{D}$.

(B) If in addition $S$ is semi-compact. Then, the sequence $\left\{x_{n}\right\}$ converges strongly to $p \in \mathcal{D}$.

Definition 3.2. (see [10]) Let $H$ be a real Hilbert space. A mapping $T: D(T) \subseteq H \rightarrow H$ is said to be $k$-asymptotically strictly pseudo-nonspreading if there exists a constant $k \in[0,1)$ and a sequence $\left\{k_{n}\right\} \subseteq[0, \infty)$ with $k_{n} \rightarrow 1(n \rightarrow \infty)$ such that

$$
\left\|T^{n} x-T^{n} y\right\|^{2} \leq k_{n}\|x-y\|^{2}+k\left\|x-T^{n} x-\left(y-T^{n}\right) y\right\|^{2}+2\left\langle x-T^{n} x, y-T^{n} y\right\rangle, \forall x, y \in D(T) .
$$

For an elegant example of $k$-asymptotically strictly pseudo-nonspreading, one can see Example 1.5 of [10]. Using definition 3.2, and Theorem 3.1 of [10], we obtain the following result.

Theorem 3.3. Let $H_{1}$ and $H_{2}$ be real Hilbert spaces. Let $A: H_{1} \rightarrow H_{2}$ be a bounded linear map such that $A \neq 0$, and $A^{*}$ be the adjoint of $A$. Let $\{S(t): t \geq 0\}: H_{1} \rightarrow H_{1}$ be a uniformly asymptotically regular asymptotically nonexpansive semigroup with a bounded measurable function $L(t):\left[0, \infty\left[\rightarrow\left[0, \infty\left[\right.\right.\right.\right.$ such that $\lim _{t \rightarrow \infty} L(t)=1$ and $M_{0}:=\bigcap_{t \geq 0} F(S(t)) \neq \emptyset$. For each $i=1,2, \cdots, N$, let $T_{i}: \mathrm{H}_{2} \rightarrow \mathrm{H}_{2}$ be a continuous uniformly L-Lipschitz and $k_{i}$ - asymptotically strictly pseudononspreading map such that $\Gamma=\bigcap_{i=1}^{N} F\left(T_{i}\right) \neq \emptyset$. Let the sequence $\left\{x_{n}\right\}$ be generated by

$$
\left\{\begin{array}{c}
x_{1} \in H_{1} \\
u_{n}=x_{n}+\gamma A^{*}\left(T_{n(\bmod N)}^{n}-I\right) A x_{n} \\
x_{n+1}=(1-\beta) u_{n}+\beta S\left(t_{n}\right) u_{n},
\end{array}\right.
$$

where $\beta \in(0,1), \gamma>0$ with $0<\gamma<\frac{1-\lambda}{M\|A\|^{2}}$ and $\left\{t_{n}\right\}$ is a sequence of positive real numbers satisfying the following conditions:

$\left(C_{1}\right) \lim t_{n}=\infty, \quad\left(C_{2}\right) \sum_{n=1}^{\infty}\left(L^{2}\left(t_{n}\right)-1\right)<\infty \quad$ and $\left(C_{3}\right) M=\sup _{n} L\left(t_{n}\right)$.

(A) Suppose $\mathcal{D}:=\left\{p \in M_{0}: A P \in \Gamma\right\} \neq \emptyset$. Then, the sequence $\left\{x_{n}\right\}$ converges weakly to $p \in \mathcal{D}$.

$(B)$ If in addition there exists $S\left(t_{*}\right) \in\{S(t): t \geq 0\}$ that is semi-compact, then, the sequence $\left\{x_{n}\right\}$ converges strongly to $p \in \mathcal{D}$.

Proof. The proof follows from the proof of Theorem 3.1 of this work and Theorem 3.1 of [10].

\section{Application and Numerical Example}

For solving split common fixed point problem, Eslamian et al. [21] proved the following result for nonexpansive semigroup.

Theorem 4.1. (ES [21]) Let $H$ and $K$ be real Hilbert spaces, $A: H \rightarrow K$ be a bounded linear operator. Let for $i=1,2, \cdots, m, \mathcal{T}_{i}:=\left\{T_{i}(t): t \geq 0\right\}$ and $\mathcal{S}_{i}:=\left\{S_{i}(t): t \geq 0\right\}$ be a finite family of u.a.r. nonexpansive semigroups on $H$ and $K$, respectively. Assume that $\Omega:=\left\{x \in \bigcap_{i=1}^{m} F\left(\mathcal{S}_{i}\right)\right.$ : 
$\left.A x \in \bigcap_{i=1}^{m} F(\mathcal{T} i)\right\} \neq \emptyset$. Suppose $f$ is a $k$-contraction of $H$ into itself. Let $\left\{x_{n}\right\}$ be a sequence generated by $x_{0} \in H$

$$
\left\{\begin{array}{c}
y_{n}=x_{n}+\sum_{i=1}^{m} \frac{1}{m} \gamma \beta A^{*}\left(\mathcal{T}_{i}\left(t_{n}\right)-I\right) A x_{n} ; \\
u_{n}=\alpha_{n, 0} x_{n}+\sum_{i=1}^{m} \alpha_{n, i} \mathcal{S}_{i}\left(t_{n}\right) y_{n} ; \\
x_{n+1}=\nu_{n} f\left(u_{n}\right)+\left(1-\nu_{n}\right) u_{n}
\end{array}\right.
$$

where $\beta \in(0,1)$, and $\gamma \in\left(0, \frac{1}{\lambda \beta}\right)$ with $\lambda$ being the spectral radius of the operator $A^{*} A$ and the sequences $\left\{\alpha_{n, i},\left\{\nu_{n}\right\}\right.$ and $\left\{t_{n}\right\}$ satisfy the following conditions:

(i) $\lim _{n \rightarrow \infty} t_{n}=\infty$ (ii) $\liminf _{n \rightarrow \infty} \alpha_{n, 0} \alpha_{n, i}>0$, for $1 \leq i \leq m$, and $\sum_{j=0}^{m} \alpha_{n, j}=1$, (iii) $\lim _{n \rightarrow \infty} \nu_{n}=0$ and $\sum_{n=0}^{\infty} \nu_{n}=\infty$. Then, the sequence $\left\{x_{n}\right\}$ converges strongly to $x^{*} \in \Omega$ which solves the variational inequality; $\left\langle x^{*}-f\left(x^{*}\right), x-x^{*}\right\rangle \geq 0, \forall x \in \Omega$.

Remark 4.2. We note that Theorem $\mathbf{E S}$ above holds if the operators $\mathcal{T}_{i}$ and $\mathcal{S}_{i}, i=1,2, \cdots, m$ are nonexpansive maps.

Let $C$ be a nonempty closed convex subset of a real Hilbert space, $H$.

A set-valued mapping $A: D(A) \subset H \rightarrow H$ is said to be monotone if for any $x, y \in D(A)$ and $x^{*} \in A x, y^{*} \in A y$, the following holds;

$$
\left\langle x-y, x^{*}-y^{*}\right\rangle \geq 0 .
$$

A monotone operator $A$ on $H$ is said to be maximal if $A$ has no monotone extension, that is, its graph is not properly contained in the graph of any other monotone operator on $H$. For a maximal monotone operator $A$ on $H$ and $r>0$, the single-valued operator $J_{r}=(I+r A)^{-1}: 2^{H} \rightarrow D(A)$, is called the resolvent of $A$. It is known (see for instance [27]), that $J_{r}$ is firmly nonexpansive, hence, it is nonexpansive. For a constant $\alpha>0$, a mapping $A: C \rightarrow H$ is said to be $\alpha$-inverse strongly monotone if for all $x, y \in C$,

$$
\langle x-y, A x-A y\rangle \geq \alpha\|A x-A y\|^{2} .
$$

Finding a point $(A+B)^{-1}(0)$ where $A, B$ are monotone operators and $(A+B)^{-1}(0)$ is the set of null points of $A+B$ is of interest in applications and has been studied extensively by many authors (see for instance, $[22,25,27]$ and the references therein).

Lemma 4.3. ([24]) Let $A: C \rightarrow H$ be an $\alpha$-inverse strongly monotone mapping. Then, for any $\sigma \in(0,2 \alpha],(I-\sigma A)$ is nonexpansive.

Lemma 4.4. ([25]) Let $A: C \rightarrow H$ be an $\alpha$-inverse strongly monotone mapping, and let $B$ be a maximal monotone operator on $H$ with $D(B) \subset C$. Then, for any $\sigma>0$, the following holds; $(A+B)^{-1}(0)=F\left(J_{\sigma}^{B}(I-\sigma A)\right)$.

By Lemma 4.3 and Lemma 4.4, we have that $\left.J_{\sigma}^{B}(I-\sigma A)\right)$ is nonexpansive.

Lemma 4.5. ( [29]) Let $E$ be a 2-uniformly smooth real Banach space and $C$ a nonempty closed convex subset of $E$. Let $T: C \rightarrow C$ be a $\lambda$ - strict pseudocontraction, with $\lambda \in(0,1)$. For $\alpha \in(0,1)$, the map $S_{\alpha}: C \rightarrow C$ defined by $S_{\alpha}=\alpha I+(1-\alpha) T$ is a nonexpansive map. Furthermore, $F\left(S_{\alpha}\right)=F(T)$.

Using Lemma 4.5 and Theorem 4.1, we obtain the following result.

Theorem 4.6. Let $H_{1}$ and $H_{2}$ be real Hilbert spaces, and $C$ a nonempty closed convex subset of $H_{2}$ and $A: H_{1} \rightarrow H_{2}$ be a bounded linear operator and let $T$ be a $\delta$ - strictly pseudocontractive self mapping on $H_{1}, \delta \in(0,1)$. For $\mu \in[\delta, 1)$, set $S_{\mu}=\mu I+(1-\mu) T$. Given any $\alpha>0$, let $\mathcal{F}: C \rightarrow H_{2}$ be $\alpha$-inverse strongly monotone, and $B: D(B) \subseteq C \rightarrow 2^{H_{2}}$ be maximal monotone with resolvent $J_{\lambda}=(I+\lambda B)^{-1}$ for any $\lambda>0$ such that $(\mathcal{F}+B)^{-1}(0) \neq \emptyset$. Assume that $\Omega:=\{x \in F(T): A x \in$ 
$\left.F\left(J_{\sigma}^{B}(I-\sigma \mathcal{F})\right)\right\} \neq \emptyset$. Suppose $f$ is a $k$-contraction mapping of $H_{1}$ into itself. Let $\left\{x_{n}\right\}$ be a sequence generated by $x_{0} \in H_{1}$

$$
\left\{\begin{array}{c}
y_{n}=x_{n}+\gamma \beta A^{*}\left(J_{\sigma_{n}}^{B}\left(I-\sigma_{n} \mathcal{F}\right)-I\right) A x_{n} \\
u_{n}=\alpha_{n} x_{n}+\left(1-\alpha_{n}\right) S_{\mu} y_{n} \\
x_{n+1}=\nu_{n} f\left(u_{n}\right)+\left(1-\nu_{n}\right) u_{n}
\end{array}\right.
$$

where $\beta \in(0,1)$, and $\gamma \in\left(0, \frac{1}{\lambda \beta}\right)$ with $\lambda$ being the spectral radius of the operator $A^{*} A$ and the sequences $\left\{\alpha_{n, i},\left\{\nu_{n}\right\}\right.$ and $\left\{\sigma_{n}\right\}$ satisfy the following conditions:

(i) $\left\{\sigma_{n}\right\}$ is a sequence in $(0, \infty)$ and there exist $a, b \in \mathbb{R}$ with $0<a \leq \sigma_{n} \leq b<2 \alpha \quad \forall n \in \mathbb{N}$. (ii) $\liminf _{n \rightarrow \infty} \alpha_{n}>0$,

(iii) $\lim _{n \rightarrow \infty} \nu_{n}=0$ and $\sum_{n=0}^{\infty} \nu_{n}=\infty$. Then, the sequence $\left\{x_{n}\right\}$ converges strongly to $x^{*} \in \Omega$ which solves the variational inequality;

$$
\left\langle x^{*}-f\left(x^{*}\right), x-x^{*}\right\rangle \geq 0, \forall x \in \Omega .
$$

Proof. Observe that the operators $J_{\sigma_{n}}^{B}\left(I-\sigma_{n} \mathcal{F}\right)$ and $S_{\mu}$ are nonexpansive. Hence, the proof follows from remark 4.2 and the proof of Theorem 4.1.

\section{$5 \quad$ Numerical Example}

We consider a numerical example in $\left(\mathbb{R}^{2},\|\cdot\|^{2}\right)$. Let $B: \mathbb{R}^{2} \rightarrow \mathbb{R}^{2}$ be defined by

$$
B\left(x_{1}, x_{2}\right)=\left(2 x_{1}-x_{2}, x_{1}+2 x_{2}\right) .
$$

Then $B$ is a maximal monotone mapping (see [20]). Next, we define $\mathcal{F}: \mathbb{R}^{2} \rightarrow \mathbb{R}^{2}$ by $\mathcal{F}\left(x_{1}, x_{2}\right)=$ $\left(\frac{x_{1}}{4}, \frac{x_{2}}{5}\right)$. Then $\mathcal{F}$ is a 2 - inverse strongly monotone mapping. We compute the resolvent operator of $B$ as follows:

$$
\begin{aligned}
\left(I+\sigma_{n} B\right)(x) & =\left(\left[x_{1}, x_{2}\right]+\sigma_{n} B(x)\right), x \in \mathbb{R}^{2} \\
& =\left(\left[x_{1}, x_{2}\right]+\sigma_{n}\left(2 x_{1}-x_{2}, x_{1}+2 x_{2}\right)\right) \\
& =\left(\left[x_{1}, x_{2}\right]+\left(2 \sigma_{n} x_{1}-\sigma_{n} x_{2}, \sigma_{n} x_{1}+2 \sigma_{n} x_{2}\right)\right)
\end{aligned}
$$

That is,

$$
\left(I+\sigma_{n} B\right)(x)=\left(\begin{array}{cc}
2 \sigma_{n}+1 & -\sigma_{n} \\
\sigma_{n} & 2 \sigma_{n}+1
\end{array}\right)\left[\begin{array}{l}
x_{1} \\
x_{2}
\end{array}\right]
$$

Therefore

$$
J_{\sigma_{n}}^{B}=\left(I+\sigma_{n} B\right)^{-1}(x)=\frac{1}{5 \sigma_{n}^{2}+4 \sigma_{n}+1}\left(\begin{array}{cc}
2 \sigma_{n}+1 & \sigma_{n} \\
-\sigma_{n} & 2 \sigma_{n}+1
\end{array}\right)\left[\begin{array}{c}
x_{1} \\
x_{2}
\end{array}\right]
$$

Now we define,

$$
A(x)=\left(\begin{array}{cc}
4 & -2 \\
1 & 3
\end{array}\right)\left[\begin{array}{c}
x_{1} \\
x_{2}
\end{array}\right]
$$

It is not difficult to see that $A$ is linear and boubded on $\mathbb{R}^{2}$. For a fixed vector $\left(\frac{1}{2}, \frac{1}{3}\right) \in \mathbb{R}^{2}$, define $T: \mathbb{R}^{2} \rightarrow \mathbb{R}^{2}$ by

$$
T x= \begin{cases}\left(\frac{1}{2}, \frac{1}{3}\right)+\frac{x}{2}, & \text { if } x \neq 0, \\ 0 & \text { if } x=0 .\end{cases}
$$

Then $T$ is $\frac{1}{4}-$ strictly pseudo contractive. For $\mu=\frac{1}{4}$, set $S_{\mu}=\mu I+(1-\mu) T$, we get from Lemma 4.5 that $S_{\mu}$ is a nonexpansive mapping. Furthermore, define $f: \mathbb{R}^{2} \rightarrow \mathbb{R}^{2}$ by $f(x)=\frac{1}{3} x$. One sees easily that $f$ is a contraction map. Set $\alpha_{n}=\frac{1}{4}+\frac{1}{n}, \nu_{n}=\frac{1}{n}$, then $\alpha_{n}=\frac{1}{4}+\frac{1}{n}, \nu_{n}=\frac{1}{n}$, satisfy 

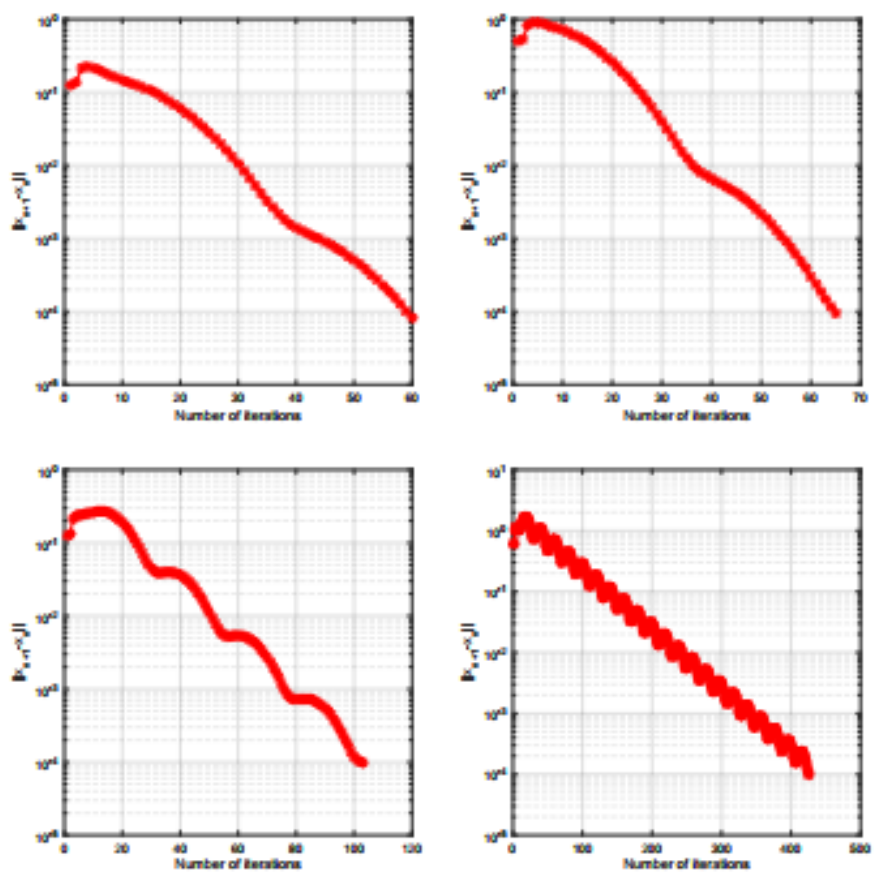

Figure 1: Error vs Number of Iterations (n):

Top Left: Case IA; Top Right: Case IB; Bottom Left: Case IIA; Bottom Right: Case IIB.

conditions (i), (ii) and (iii) of Theorem 4.6. With the operators $A, B, f, \mathcal{F}, S_{\mu}, T$ and parameters $\alpha_{n}, \sigma_{n}, \nu_{n}$ defined above, $H_{1}=H_{2}=\mathbb{R}^{2}$

then algorithm (4.4) becomes

$$
\left\{\begin{array}{l}
y_{n}=\left(x_{1, n}, x_{2, n}\right)+\gamma \beta A^{*}\left(J_{\sigma_{n}}^{B}\left(I-\frac{1}{2}\left(\frac{x_{1}}{4}, \frac{x_{2}}{5}\right)-I\right)\left(\begin{array}{cc}
4 & -2 \\
1 & 3
\end{array}\right)\left[\begin{array}{c}
x_{1, n} \\
x_{2, n} .
\end{array}\right]\right. \\
u_{n}=\left(\frac{1}{4}+\frac{1}{n}\right)\left(x_{1, n}, x_{2, n}\right)+\left(\frac{3}{4}-\frac{1}{n}\right) S_{\mu} y_{n} \\
\quad x_{n+1}=\frac{1}{n} \frac{1}{3}\left(u_{n}\right)+\left(1-\frac{1}{n}\right) u_{n},
\end{array}\right.
$$

where $\beta \in(0,1)$, and $\gamma \in\left(0, \frac{1}{\lambda \beta}\right)$ with $\lambda$ being the spectral radius of the operator $A^{*} A$ Now we plot the the graphs of error against number for iterations by considering two different cases of starting points

Case 1A: $x_{0}=(0.4,-0.25)^{T}, \sigma_{n}=0.5, \quad$ Case IB: $x_{0}=(-6,5)^{T}, \sigma_{n}=0.5$

Case IIA: $x_{0}=(0.4,-0.25)^{T}, \sigma_{n}=100, \quad$ Case IIB: $x_{0}=(-6,5)^{T}, \sigma_{n}=1000$

Remark 5.1. In Theorem 3.1, we required that the step size, $\gamma$ satisfy the condition $0<\gamma<\frac{1-\lambda}{M \|\left. A\right|^{2}}$. This is restrictive since the norm of the bounded linear operator, $A$ is not known precisely. It is known that computation of the norm of $A$ is very difficult in general and in some cases impossible. Although the result obtained in Theorem 3.1 is correct and novel, it will be of interest to obtain the same result with a more realistic condition on the step size, $\gamma$. It is the purpose of the next Theorem of this article to address this concern. 


\subsection{Algorithm without Prior Knowledge of Operator Norm}

Theorem 5.2. Let $H_{1}$ and $H_{2}$ be real Hilbert spaces. Let $A: H_{1} \rightarrow H_{2}$ be a bounded linear map such that $A \neq 0$, and $A^{*}$ be the adjoint of $A$. Let $\{S(t): t \geq 0\}: H_{1} \rightarrow H_{1}$ be a uniformly asymptotically regular asymptotically nonexpansive semigroup with a bounded measurable function $L(t):\left[0, \infty\left[\rightarrow\left[0, \infty\left[\right.\right.\right.\right.$ such that $\lim _{t \rightarrow \infty} L(t)=1$ and $M_{0}:=\bigcap_{t \geq 0} F(S(t)) \neq \emptyset$. Let $T: H_{2} \rightarrow H_{2}$ be an L-Lipschitz and $\lambda$-strictly pseudo-nonspreading map such that $F(T) \neq \emptyset$. For $\alpha \in[\lambda, 1)$, set $T_{\alpha}=$ $\alpha I+(1-\alpha) T$ and let the sequence $\left\{x_{n}\right\}$ be generated by

$$
\left\{\begin{array}{l}
x_{1} \in H_{1} \\
u_{n}=x_{n}-\gamma_{n} A^{*}\left(I-T_{\alpha}\right) A x_{n} \\
\quad x_{n+1}=(1-\beta) u_{n}+\beta S\left(t_{n}\right) u_{n}
\end{array}\right.
$$

where $\beta \in(0,1)$,

$C_{1}$ for $\epsilon>0$ small enough $\gamma_{n} \in\left(\epsilon, \frac{\left\|A x_{n}-T A x_{n}\right\|}{\left\|A^{*}\left(A x_{n}-T\right) A x_{n}\right\|}-\epsilon\right)$ if $A x_{n} \neq T A x_{n}$ otherwiwise take $\gamma_{n}=\gamma$, (where $\gamma$ is a nonnegative constant) :

$\left(C_{2}\right)\left\{t_{n}\right\}$ is a sequence of positive real numbers satisfying the following conditions $\lim t_{n}=\infty$, $\left(C_{3}\right) \sum_{n=1}^{\infty}\left(L^{2}\left(t_{n}\right)-1\right)<\infty$ and $\left(C_{4}\right) M=\sup _{n} L\left(t_{n}\right)$.

(A) Suppose $\mathcal{D}:=\left\{p \in M_{0}: A p \in F(T)\right\} \neq \emptyset$. Then, the sequence $\left\{x_{n}\right\}$ converges weakly to $p \in \mathcal{D}$.

(B) If in addition there exists $S\left(t_{*}\right) \in\{S(t): t \geq 0\}$ that is semi-compact. Then, the sequence $\left\{x_{n}\right\}$ converges strongly to $p \in \mathcal{D}$.

Proof. Step 1. We prove that $\left\{x_{n}\right\}$ is bounded .

Let $p \in \mathcal{D}$. Then, $p \in M_{0}$ and $A p \in F(T)$. We compute as follows:

$$
\begin{aligned}
\left\|u_{n}-p\right\|^{2} & =\left\|x_{n}-\gamma_{n} A^{*}\left(I-T_{\alpha}\right) A x_{n}-p\right\|^{2} \\
& =\left\|x_{n}-p\right\|^{2}-2 \gamma_{n}\left\langle x_{n}-p, A^{*}\left(I-T_{\alpha}\right) A x_{n}\right\rangle+\gamma_{n}^{2}\left\|A^{*}\left(I-T_{\alpha}\right) A x_{n}\right\|^{2} \\
& =\left\|x_{n}-p\right\|^{2}-2 \gamma_{n}\left\langle A\left(x_{n}-p\right),\left(I-T_{\alpha}\right) A x_{n}\right\rangle+\gamma_{n}^{2}\left\|A^{*}\left(I-T_{\alpha}\right) A x_{n}\right\|^{2} \\
& =\left\|x_{n}-p\right\|^{2}-2 \gamma_{n}\left\langle A x_{n}-T_{\alpha} A x_{n}+T_{\alpha} A x_{n}-A p,\left(I-T_{\alpha}\right) A x_{n}\right\rangle+\gamma_{n}^{2}\left\|A^{*}\left(I-T_{\alpha}\right) A x_{n}\right\|^{2} \\
& =\left\|x_{n}-p\right\|^{2}-2 \gamma_{n}\left\|\left(I-T_{\alpha}\right) A x_{n}\right\|^{2}-2 \gamma_{n}\left\langle T_{\alpha} A x_{n}-A p,\left(I-T_{\alpha}\right) A x_{n}\right\rangle+\gamma_{n}^{2}\left\|A^{*}\left(I-T_{\alpha}\right) A x_{n}\right\|^{2} \\
& \leq\left\|x_{n}-p\right\|^{2}-2 \gamma_{n}\left\|\left(I-T_{\alpha}\right) A x_{n}\right\|^{2}+\gamma_{n}\left\|\left(I-T_{\alpha}\right) A x_{n}\right\|^{2} \\
& +\gamma_{n}^{2}\left\|A^{*}\left(I-T_{\alpha}\right) A x_{n}\right\|^{2}(\text { by Lemma } 2.16) \\
& =\left\|x_{n}-p\right\|^{2}-\gamma_{n}\left\|\left(I-T_{\alpha}\right) A x_{n}\right\|^{2}+\gamma_{n}^{2}\left\|A^{*}\left(I-T_{\alpha}\right) A x_{n}\right\|^{2} \\
& =\left\|x_{n}-p\right\|^{2}-\gamma_{n}\left(\left\|\left(I-T_{\alpha}\right) A x_{n}\right\|^{2}-\gamma_{n}\left\|A^{*}\left(I-T_{\alpha}\right) A x_{n}\right\|^{2}\right) \\
& \leq\left\|x_{n}-p\right\|^{2}\left(\text { by } C_{1}\right)
\end{aligned}
$$

Utilizing convexity of $\|\cdot\|^{2}$, we have

$$
\begin{aligned}
\left\|x_{n+1}-p\right\|^{2} & =\left\|(1-\beta) u_{n}+\beta S\left(t_{n}\right) u_{n}-p\right\|^{2} \\
& \leq(1-\beta)\left\|u_{n}-p\right\|^{2}+\beta\left\|S\left(t_{n}\right) u_{n}-p\right\|^{2} \\
& \leq(1-\beta)\left\|x_{n}-p\right\|^{2}+\beta L^{2}\left(t_{n}\right)\left\|x_{n}-p\right\|^{2} \\
& =\left[1+\beta\left(L^{2}\left(t_{n}\right)-1\right)\right]\left\|x_{n}-p\right\|^{2}
\end{aligned}
$$

By Lemma 2.10, we have that

$$
\lim _{n \rightarrow \infty}\left\|x_{n}-p\right\| \text { exists }
$$

Consequently, $\left\{x_{n}\right\}$ and $\left\{u_{n}\right\}$ are bounded. 
Step 2: $\lim _{n \rightarrow \infty}\left\|x_{n+1}-x_{n}\right\|=0$

By Lemma 2.9, equation (5.3) and inequality (5.4), we have:

$$
\begin{aligned}
\left\|x_{n+1}-p\right\|^{2} & =\left\|(1-\beta) u_{n}+\beta S\left(t_{n}\right) u_{n}-p\right\|^{2} \\
& =(1-\beta)\left\|u_{n}-p\right\|^{2}+\beta\left\|S\left(t_{n}\right) u_{n}-p\right\|^{2}-\beta(1-\beta)\left\|S\left(t_{n}\right) u_{n}-u_{n}\right\|^{2} \\
& \leq(1-\beta)\left\|u_{n}-p\right\|^{2}+\beta L^{2}\left(t_{n}\right)\left\|u_{n}-p\right\|^{2}-\beta(1-\beta)\left\|S\left(t_{n}\right) u_{n}-u_{n}\right\|^{2} \\
& =\left[1+\beta\left(L^{2}\left(t_{n}\right)-1\right)\right]\left\|u_{n}-p\right\|^{2}-\beta(1-\beta)\left\|S\left(t_{n}\right) u_{n}-u_{n}\right\|^{2} \\
& =\left[1+\beta\left(L^{2}\left(t_{n}\right)-1\right)\right]\left[\left\|x_{n}-p\right\|^{2}-\gamma_{n}\left(\left\|\left(I-T_{\alpha}\right) A x_{n}\right\|^{2}-\gamma_{n}\left\|A^{*}\left(I-T_{\alpha}\right) A x_{n}\right\|^{2}\right)\right] \\
& -\beta(1-\beta)\left\|S\left(t_{n}\right) u_{n}-u_{n}\right\|^{2}
\end{aligned}
$$

Utilizing Lemma 2.10 and condition $C_{3}$, we obtain that $\lim \left\|x_{n}-p\right\|$ exists. From (5.7), we obtain

$$
\begin{aligned}
& {\left[1+\beta\left(L^{2}\left(t_{n}\right)-1\right)\right] \gamma_{n}\left(\left\|\left(I-T_{\alpha}\right) A x_{n}\right\|^{2}-\gamma_{n}\left\|A^{*}\left(I-T_{\alpha}\right) A x_{n}\right\|^{2}\right) \leq\left[1+\beta\left(L^{2}\left(t_{n}\right)-1\right)\right]\left\|x_{n}-p\right\|^{2} } \\
- & \left\|x_{n+1}-p\right\|^{2} \\
= & \left.\left\|x_{n}-p\right\|^{2}+\beta\left(L^{2}\left(t_{n}\right)-1\right)\right]\left\|x_{n}-p\right\|^{2}-\left\|x_{n+1}-p\right\|^{2} \rightarrow 0 \text { by condition } C_{3}
\end{aligned}
$$

Consequently,

$$
\gamma_{n}\left(\left\|\left(I-T_{\alpha}\right) A x_{n}\right\|^{2}-\gamma_{n}\left\|A^{*}\left(I-T_{\alpha}\right) A x_{n}\right\|^{2}\right) \rightarrow 0
$$

From $C_{1}$, it follows that

$$
\gamma_{n}<\frac{\left\|\left(I-T_{\alpha}\right) A x_{n}\right\|^{2}}{\left\|A^{*}\left(I-T_{\alpha}\right) A x_{n}\right\|^{2}}-\epsilon
$$

So $\gamma_{n}\left\|A^{*}\left(I-T_{\alpha}\right) A x_{n}\right\|^{2}<\left\|\left(I-T_{\alpha}\right) A x_{n}\right\|^{2}-\epsilon\left\|A^{*}\left(I-T_{\alpha}\right) A x_{n}\right\|^{2}$, which gives

$$
\epsilon\left\|A^{*}\left(I-T_{\alpha}\right) A x_{n}\right\|^{2}<\left\|\left(I-T_{\alpha}\right) A x_{n}\right\|^{2}-\gamma_{n}\left\|A^{*}\left(I-T_{\alpha}\right) A x_{n}\right\|^{2} \rightarrow 0
$$

That is

$$
\left\|A^{*}\left(I-T_{\alpha}\right) A x_{n}\right\| \rightarrow 0
$$

Furthermore, it follows from (5.7) that

$$
\begin{aligned}
\epsilon\left\|\left(I-T_{\alpha}\right) A x_{n}\right\|^{2} & <\gamma_{n}\left\|\left(I-T_{\alpha}\right) A x_{n}\right\|^{2} \\
& \leq\left[1+\beta\left(L^{2}\left(t_{n}\right)-1\right)\right]\left\|x_{n}-p\right\|^{2}-\left\|x_{n+1}-p\right\|^{2}+\gamma_{n}^{2}\left\|A^{*}\left(I-T_{\alpha}\right) A x_{n}\right\|^{2}\left(5_{\sharp} 1 \mathrm{C} .\right)
\end{aligned}
$$

Hence,

$$
\left\|\left(I-T_{\alpha}\right) A x_{n}\right\| \rightarrow 0
$$

Notice from (5.7) that

$$
\begin{aligned}
\beta(1-\beta)\left\|S\left(t_{n}\right) u_{n}-u_{n}\right\|^{2} & \leq\left[1+\beta\left(L^{2}\left(t_{n}\right)-1\right)\right]\left\|x_{n}-p\right\|^{2}-\left\|x_{n+1}-p\right\|^{2} \\
& =\left\|x_{n}-p\right\|^{2}+\beta\left(L^{2}\left(t_{n}\right)-1\right)\left\|x_{n}-p\right\|^{2}-\left\|x_{n+1}-p\right\|^{2} \rightarrow \emptyset 5
\end{aligned}
$$

That is

$$
\lim _{n \rightarrow \infty}\left\|S\left(t_{n}\right) u_{n}-u_{n}\right\|=0
$$

From (5.4), we get that $\lim _{n \rightarrow \infty}\left\|u_{n}-p\right\|$ exists. and from (5.3), $\left\|u_{n}-x_{n}\right\|=\gamma_{n}\left\|A^{*}\left(I-T_{\alpha}\right) A x_{n}\right\| \rightarrow$ 0 . Observe that

$$
\left\|x_{n}-S\left(t_{n}\right) u_{n}\right\| \leq\left\|x_{n}-u_{n}\right\|+\left\|S\left(t_{n}\right) u_{n}-u_{n}\right\| \rightarrow 0
$$




$$
\left\|x_{n+1}-S\left(t_{n}\right) u_{n}\right\| \leq(1-\beta)\left\|S\left(t_{n}\right) u_{n}-u_{n}\right\| \rightarrow 0
$$

Thus,

$$
\left\|x_{n+1}-x_{n}\right\| \leq\left\|x_{n+1}-S\left(t_{n}\right) u_{n}\right\|+\left\|x_{n}-S\left(t_{n}\right) u_{n}\right\| \rightarrow 0
$$

Step 3. We show that $\lim \left\|u_{n}-S(t) u_{n}\right\|=0, \quad \forall t \geq 0$.

Since $\{S(t): t \geq 0\}$ is uniformly asymptotically regular and $\lim t_{n}=\infty$, also, $t \mapsto S(\cdot) x$ is continuous for each $x \in H_{1}$, then, we have:

$$
\lim _{n \rightarrow \infty}\left\|S(t) S\left(t_{n}\right) u_{n}-S\left(t_{n}\right) u_{n}\right\| \leq \limsup _{n \rightarrow \infty}\left\|S(t) S\left(t_{n}\right) x-S\left(t_{n}\right) x\right\| \rightarrow 0 .
$$

Thus,

$$
\left\|u_{n}-S(t) u_{n}\right\| \leq\left\|u_{n}-S\left(t_{n}\right) u_{n}\right\|+\left\|S\left(t_{n}\right) u_{n}-S(t) S\left(t_{n}\right) u_{n}\right\|+\left\|S(t) S\left(t_{n}\right) u_{n}-S(t) u_{n}\right\| .
$$

This implies that $\left\|u_{n}-S(t) u_{n}\right\| \rightarrow 0$ as $n \rightarrow \infty$.

Step 4. We show that the sequence $\left\{x_{n}\right\}$ converges weakly to a point $p \in \mathcal{D}$.

Since $\left\{x_{n}\right\}$ is bounded, then, there exists a subsequence $\left\{x_{n_{j}}\right\}$ of $\left\{x_{n}\right\}$ such that $x_{n_{j}} \rightarrow p$ as $j \rightarrow \infty$.

But $S(t)$ is asymptotically nonexpansive, for each $t \geq 0$. Then, by Lemma $2.12, S(t)$ is demi-closed at 0 . Hence, $p \in F(S(t)) \forall t \geq 0$.. That is $p \in \cap_{t \geq 0} F(S(t))$.

Furthermore, $A$ is a bounded linear operator. Hence, $\left\{A x_{n_{j}}\right\}$ converges weakly to $A p$. From equation (3.15), we obtain that $\lim \left\|(T-I) A x_{n_{j}}\right\|=0$. By demi-closedness of $T$ at 0 , it follows that $A p \in F(T)$. Hence, $p \in \mathcal{D}$.

Next we show that $p$ is unique. Assume for contradiction, that there exists another subsequence $\left\{x_{n_{k}}\right\}$ of $\left\{x_{n}\right\}$ such that $x_{n_{k}} \rightarrow u^{*}$ as $k \rightarrow \infty$, where $p \neq u^{*}$. Recall that from Ste 4 above $\left\{x_{n_{j}}\right\}$ is a subsequence of $\left\{x_{n}\right\}$ such that $x_{n_{j}} \rightarrow p$ as $j \rightarrow \infty$. Using similar arguments as those of step 4, one can show that $u^{*} \in \mathcal{D}$. By Remark 2.17, we know that $H_{1}$ satisfies Opial condition, hence we have:

$$
\begin{aligned}
\liminf _{k \rightarrow \infty}\left\|x_{n_{k}}-p\right\| & <\liminf _{k \rightarrow \infty}\left\|x_{n_{k}}-u^{*}\right\| \\
& =\lim _{n \rightarrow \infty}\left\|x_{n}-u^{*}\right\| \\
& =\liminf _{j \rightarrow \infty}\left\|x_{n_{j}}-u^{*}\right\| \\
& <\liminf _{j \rightarrow \infty}\left\|x_{n_{j}}-p\right\| \\
& =\lim _{n \rightarrow \infty}\left\|x_{n}-p\right\| \\
& =\liminf _{k \rightarrow \infty}\left\|x_{n_{k}}-p\right\| .
\end{aligned}
$$

Hence, a contradiction. Therefore, $x_{n} \rightarrow p$ as $n \rightarrow \infty$. This completes the proof conclusion $(A)$.

Next, we proof for condition $(B)$

Since there exists $S\left(t_{*}\right) \in\{S(t): t \geq 0\}$ that is semi-compact and $\lim \left\|u_{n}-S(t) u_{n}\right\|=0 \forall t \geq 0$, then, there exists a subsequence $\left\{u_{n_{j}}\right\}$ of $\left\{u_{n}\right\}$ such that $\left\{u_{n_{j}}\right\}$ converges strongly to $\varkappa^{*} \in H_{1}$. Applying equation (3.16) and the fact that $\left\{u_{n_{j}}\right\}$ converges strongly to $\varkappa^{*} \in H_{1}$, we obtain that there exists a subsequence $\left\{x_{n_{j}}\right\}$ of $\left\{x_{n}\right\}$ which converges strongly to $\varkappa^{*}$. Since $\left\{x_{n}\right\}$ converges weakly to $p$, then, $\varkappa^{*}=p$. Furthermore, $\lim \left\|x_{n}-p\right\|$ exists and $\lim \left\|x_{n_{j}}-p\right\|=0$. Therefore, $\left\{x_{n}\right\}$ converges strongly to $p \in \mathcal{D}$. This completes the proof of conclusion $(B)$. 
Conclusion: In this work, we proved weak and strong convergence Theorems for solving split feasibility problem involving a strictly pseudo-nonspreading mapping and asymptotically nonexpansive semigroup in infinite dimensional real Hilbert spaces. The results complement those of Cholamjiak and Shehu [11], in that the class of strictly pseudo-nonspreading mappings we considered is different from the class of strictly pseudo-contractive mappings considered by Cholamjiak and Shehu [11]. Ezeora and Ogbonna [13], and many others. Utilizing result of Eslamian et al. [21], we studied split feasibility problem in which one of the problems is a monotone inclusion problem, a problem of contemporary interest in optimization theory, see Theorem 4.6 above. Using Theorem 4.6, a numerical example is presented.

As we observed in remark 5.1, the condition on the step size, $\gamma$ is restrictive . A search to remove such restriction has been made by many authors and many results have been obtained. See for instance, [28], [19], [26] and the refernces therein. To prove their results, some authors (see [19]) require that the operator studied should satisfy the so-called type $P$ condition. It is known that in infinte dimensional Hilbert space, type $\mathrm{P}$ condition coincides with the operator being firmly nonexpansive. Of course, it is a well known fact that firmly nonexpansive maps with nonempty fixed point sets are firmly quasi nonexansive and so they are quasi nonexpansive. In Theorem 5.2, we removed the restictive condition on the step size $\gamma$ and obtained same result as that of Theorem 5.4 of our article. We achieved this when the operator is quasi nonexpansive, and dispensed with the requirement that the ooerator should be of type $\mathrm{P}$.

\section{Acknowledgements}

The authors thank immensely the referees for insightful comments that helped improve on the quality of the original manuscript.

\section{References}

[1] Censor Y., Elfving T., A multi-projection algorithm using Bregman projections in a product space, Numer. Algor. 8 (1994) 221-239, 1272-1276.

[2] Byrne.C; Iterative oblique projection onto convex sets and the split feasibility problem, Inverse Probl. 18, 441-453, (2002).

[3] Byrne .C; A unified treatment of some iterative algorithms in signal processing and image reconstruction, Inverse Probl. 20, 103-120, (2004).

[4] Quan .J, Chang .S. S , Zhang .X; Multiple-set split feasibility problems for k-strictly pseudononspreading mapping in Hilbert spaces, . Abstr. Appl. Anal. 2013, Article ID 342545, (2013), doi:10.1155/2013/342545 14 .

[5] Xu .H. K; Iterative methods for the split feasibility problem in infinite-dimensional Hilbert spaces, Inverse Probl. 26, 105018, (2010).

[6] Moudafi A. A note on the split common fixed-point problem for quasi-nonexpansive operators Nonlinear Analysis 74 (2011) 4083-4087.

[7] Censor Y., Segal A., The split common fixed point problem for directed operators, J. Convex Anal. 16 (2009) 587-600.

[8] Osilike, M. O, Isiogugu, F. O; Weak and strong convergence theorems for nonspreadingtypemappings in Hilbert spaces, Nonlinear Anal. 74, 1814-1822 (2011).

[9] Liu, Q. H.: Convergence theorems of the sequence of iterates for asymptotically demicontractive and hemicontractive mappings. Nonlinear Anal., Theory Methods Appl. 26(11) (1996), 18351842 
[10] Quan J., Chang S. S.; Multiple-set split feasibility problems for $k$-asymptotically strictly pseudononspreading mappings in Hilbert spaces, Journal of Inequalities and Applications, 2014, 2014:69.

[11] Cholamjiak P., Shehu Y. Iterative approximation for split common fixed point problem involving an asymptotically nonexpansive semigroup and a total asymptotically strict-pseudocontraction . Fixed Point Theory and Applications 2014, 2014:131.

[12] Yu Z. T. , Lin L. J. ; Variational inequality problems over split fixed point sets of strict pseudononspreading mappings and quasi-nonexpansive mappings with applications, Fixed Point Theory and Applications, 2014, 2014: 198.

[13] Ezeora J. N. , Ogbonna R. Split Feasibility Problem For countable Family of Multi-valued nonlinear mappings Mathematickii Vesnik 70, 3 (2018), 233-242.

[14] Goebel K., Kirk.W. A; A fixed point theorem for asymptotically nonexpansive mappings, Proc. Am. Math. Soc.35, 171-174,(1972).

[15] Chen, R, Song, Y: Convergence to common fixed point of nonexpansive semigroup. J. Comput. Appl. Math. 200, 566-575 (2007)

[16] Song, Y, Xu S: Strong convergence theorems for nonexpansive semigroup in Banach spaces. J. Math. Anal. Appl.338, (2008) 152-161.

[17] Tan .K. K. , Xu .H. K; Approximating fixed points of nonexpansive mappings by the Ishikawa iteration process, .J. Math. Anal. Appl. 178, 301-308(1993).

[18] Chang .S. S, Cho .Y. J , Zhou .H; Demi-closed principle and weak convergence problems for asymptotically nonexpansive mappings, .J. Korean Math. Soc. 38, 1245-1260 (2001).

[19] Izuchukwu C., Okeke C. C. and Isiogugu F. O. A viscosity iterative technique for split variational inclusion and fixed point problems between a Hilbert space and aBanach space $J$. Fixed Point Theory Appl. (2018) 20:157https://doi.org/10.1007/s11784-018-0632-4

[20] Abass H. A., Izuchukwu C. , Mewomo O. T., Oyewole O. K. On Split Equality Monotone Yoshida variational Inclusion and Fixed Point problems for Countable Infinite Families of certain Nonlinear Mappings in Hilbert spaces Novi Sad J. Math. 2020-03-01. https://doi.org/10.30755/NSJOM.10119

[21] Eslamian M. Vahidi J. Split Common Fixed Point Problem of Nonexpansive Semigroup Mediterr. J. Math. DOI 10.1007/s00009-015-0541-3

[22] Ezeora J. N. , Strong convergence theorem for monotone operators and strict pseudononspreading mapping. Adv. in fixed point Theory, 8(3) (2018), 259-273.

[23] Lin W.,Zhaoli M. The split common fixed point problem for asymptotically nonexpansive semigroups in Banachs paces, Fixed Point Theory and Applications, (2016), 2016:94 DOI 10.1186/s13663-016-0588-2.

[24] Lin L., Takahashi W., A general iterative method for hierarchical variational inequality problems in Hilbert spaces and applications, Positivity 16 (2012), 429-453.

[25] Manaka H. , Takahashi W. , Weak convergence theorems for maximal monotone operators with nonspreading mappings in a Hilbert space, Cubo, vol. 13, no. 1, (2011), 11-24.

[26] Suparatulatorn R. , Prasit Cholamjiak P. and Suantai S. Self-adaptive algorithms with inertial effects for solvingthe split problem of the demicontractive operators RACSAM (2020) 114:40 https://doi.org/10.1007/s13398-019-00737-x 
[27] Takahashi S., Takahashi W. , Toyoda M. , Strong convergence theorems for maximal monotone operators with nonlinear mappings in Hilbert spaces, J. Optim. Theory and Appl., vol. 147, no. $1,(2010), 27-41$.

[28] Zhao J. Songnian H. Solving the General Split Common Fixed-Point Problem of QuasiNonexpansive Mappings without Prior Knowledge of Operator Norms Filomat 31(3) (2017) $559-573$

[29] Zhou H. ; Convergence theorems for fixed points of $k$ - strict pseudocontracrions in Hilbert spaces. Nonlinear Anal. Vol. 69(8) 2008. 3160-3173. 